\title{
Knowledge and opinions of parents of children hospitalized in hematologyl oncology units regarding complementary and alternative medicine
}

\author{
Gülzade Uysal ${ }^{1 a}$, Duygu Sönmez Düzkaya² ${ }^{2}$ and Ayşe Karakoç3 \\ ${ }^{1}$ Faculty of Health Science, Department of Nursing, Okan University, Turkey \\ ${ }^{2}$ Istanbul Faculty of Medicine, Directorate of Nursing Services, Istanbul University, Turkey \\ ${ }^{3}$ School of Health Science, Department of Midwifery, Marmara University, Turkey
}

\begin{abstract}
The current study aimed to determine the knowledge and opinions of parents who had children with cancer regarding complementary and alternative medicine. This descriptive study was performed with 145 parents. Data collection was implemented by means of a literature-based questionnaire. Of the parents who were enrolled into the study, $42.1 \%$ were aged 36 years or older and $57.2 \%$ had primary school education only. A total of $86.9 \%$ of the information was gathered from the mothers of the children. All parents preferred CAM therapies for their children's treatment; more than half used herbs as CAM, and $81.4 \%$ of the parents who used CAM with held this information from healthcare professionals. All parents had insufficient knowledge about complementary and alternative treatments, including those who had opted out of conventional medicine, but wanted to learn more about them. Therefore, healthcare professionals should improve their knowledge of CAM methods and be able to appropriately enlighten parents while providing an environment in which families can freely discuss information. Keywords: Child, cancer, parent, complementary and alternative practices.
\end{abstract}

\section{Introduction}

Complementary and alternative medicine (CAM) therapies are frequently used to support modern medical treatments in adult and pediatric patients. They are used often, especially for diseases that prove difficult to cure, such as cancer, and repetitive and chronic diseases, such as asthma. Families turn towards CAM therapies due to the fact that childhood cancers have increased in number and threaten life. Studies have shown that the use of CAM in treating childhood cancers and reducing symptoms have gradually increased [1-5].

\footnotetext{
${ }^{a}$ Corresponding author: gulzade.uysal@okan.edu.tr
} 
The frequency of CAM therapy use for childhood cancers is between $24 \%$ and $90 \%$ [6]. The reported reasons for choosing CAM therapies among parents that have children with cancer are preventing/reducing the adverse effects of medical treatment; wanting to do everything they can for their children; slowing the progression of cancer; and strengthening the immune system $[2,3,5,7-11]$. However, when studies regarding CAM therapies and their use are analyzed, it can be observed that there are few studies about pediatric patients and their parents. The aim of this study was to determine the knowledge and opinions regarding CAM therapies of parents with children who were hospitalized in hematology/oncology units because of cancer.

\section{Method}

The current study aimed to determine the knowledge and opinions of parents who had children with cancer regarding complementary and alternative medicine.

\subsection{Participants}

This is a descriptive cross-sectional study performed with parents of children who had been diagnosed as having cancer, aged 0-18 years, in a hematology/oncology unit of a training research hospital between February 2015, and June 2015. The samples consisted of 145 parents whose children were hospitalized between the set dates and volunteered to participate in the study.

\subsection{Procedure}

The data collection tools were prepared by the researchers in view of the literature and comprised 20 questions regarding the socio-demographic and condition-related characteristics of the patients and parents, and semi-structured forms that included 3-point Likert-type (Agree, Not sure, Disagree) questions regarding the parents' knowledge and opinions of CAM.

This study was organized in accordance with the Declaration of Helsinki and was given written approval by the University Research Committee. Oral and written consents were taken from all the parents that participated in the study.

The collected data in the study were analyzed through descriptive statistical calculations using the SPSS version 17.0 program.

\section{Findings}

Of the children who participated in the study, 42.1\% were aged between 6 and 10 years, $50.3 \%$ were female, and $77.2 \%$ were hospitalized with the diagnosis of ALL. Some $59.3 \%$ were attending school and $47.6 \%$ had had their disease for less than a year. The mothers of $86.9 \%$ of the patients were informed and involved in discussions. Of the parents, $42.1 \%$ were aged 36 years or older, $88.3 \%$ were married, and more than half $(57.2 \%)$ had primary school education only (Table 1). 
Table 1. Descriptive Characteristics of Children and Parents $(n=145)$

\begin{tabular}{|c|c|c|c|}
\hline \multirow{2}{*}{ Age } & & $\mathbf{n}$ & $\mathbf{\%}$ \\
& $1-5$ years & 38 & 26.2 \\
\multirow{2}{*}{ Sex } & 6-10 years & 61 & 42.1 \\
& 11 years and above & 46 & 31.7 \\
\hline \multirow{2}{*}{ Diagnosis } & Female & 73 & 50.3 \\
& Male & 72 & 49.7 \\
\hline \multirow{2}{*}{ Attending school } & ALL & 111 & 77.2 \\
& Other* & 33 & 22.8 \\
\hline \multirow{2}{*}{ Year of illness } & Yes & 86 & 59.3 \\
& No & 59 & 40.7 \\
\hline \multirow{2}{*}{ Interviewed } & Under 1 year & 69 & 47.6 \\
\hline \multirow{2}{*}{ Parents } & $1-3$ years & 50 & 34.5 \\
& More than 4 years & 26 & 17.9 \\
\hline \multirow{2}{*}{ Marital status } & Mother & 126 & 86.9 \\
& Father & 19 & 13.1 \\
\hline \multirow{2}{*}{ Graduation } & $17-27$ years & 34 & 23.4 \\
& $28-35$ years & 50 & 34.5 \\
\hline Total & 36 years and over & 61 & 42.1 \\
\hline
\end{tabular}

* XLPS, Hemolytic anemia, Ewing's sarcoma, osteosarcoma

It was determined that all parents had used CAM therapies during their child's treatment. After analyzing the methods that were used, it was discovered that $53.8 \%$ of the parents used herbs, $22.7 \%$ spiritual/physical practices, $15.2 \%$ aromatherapy, and $8.3 \%$ manipulative and body-based treatments. At the end of CAM therapies, $38.5 \%$ of the parents stated that it had had a positive effect on the treatment, $30.8 \%$ said it had had a negative effect, whereas $26.9 \%$ expressed that it had had no impact on the treatment process (Table 2).

Of the entire parent population, $76.6 \%$ thought that CAM therapies were used to reduce adverse effects, $50 \%$ to support treatment, and $34.6 \%$ to provide treatment. Additionally, $19.2 \%$ declared that they used the methods as "a last resort" (Table 2).

Some $40.7 \%$ of the parents stated they had information about CAM therapies and their sources were relatives/friends $(37.2 \%)$, media $(22.8 \%)$, plant scientists/herbalists $(15.9 \%)$, and $9.7 \%$ said they received information through other oncology patients and patient's relatives. Furthermore, $95.2 \%$ of the parents also stated they wanted information on CAM therapies (Table 3). 
Table 2. Status of parents using CAM methods $(\mathrm{n}=145)$

\begin{tabular}{|l|c|c|}
\hline & $\mathbf{n}$ & $\mathbf{\%}$ \\
\hline The methods used & & \\
*Herb & 78 & 53.8 \\
Spiritual/physical practices & 33 & 22.7 \\
Aromatherapy & 22 & 15.2 \\
Manipulative and body-based & 12 & 8.3 \\
treatments & & \\
\hline$* *$ The reason for using CAM & 111 & 76.5 \\
Reducing adverse effects & 73 & 50.3 \\
Supporting the treatment & 50 & 34.4 \\
Providing treatment/Treating & 27 & 18.6 \\
As a last resort & & \\
\hline Changes after CAM use & & \\
It had a positive effect on the & 55 & 38.0 \\
treatment & 45 & 31.0 \\
It had a negative effect on the & 39 & 26.8 \\
treatment & 6 & 4.2 \\
There were no changes & & \\
It reduced the adverse effects of the \\
treatment
\end{tabular}

*Stinging nettle, cumin, reishi mushroom, turmeric, herbal tea...

**Parents who use CAM gave multiple answers.

The knowledge and opinions of parents regarding CAM therapies are shown in Table 4. Some $81.4 \%$ of the parents agreed with the statement "I hide the fact that I use CAM therapies from healthcare professionals"; $44.8 \%$ agreed with "I shy away from asking healthcare professionals questions about CAM therapies"; and 36.6\% agreed with "I think healthcare professionals will judge me for using CAM therapies." In contrast, statements of "Using CAM therapies alone is more effective"; "CAM therapies may affect treatment negatively"; and "CAM therapies can be used throughout the duration of the disease" were answered with "not sure" by nearly half of the parents (Table 4).

Table 3. Knowledge of parents regarding CAM methods $(n=145)$

\begin{tabular}{|l|l|c|c|}
\hline \multicolumn{2}{|l|}{} & $\mathbf{n}$ & $\mathbf{\%}$ \\
\hline Receiving information & Yes & 59 & 40.7 \\
& No & 74 & 51.0 \\
& I do not remember & 12 & 8.3 \\
\hline & Relatives/friends & 54 & \\
& Through media & 33 & 37.2 \\
Source of information* & Plant scientists/herbalists & 23 & 22.8 \\
& Oncology patients/patient relatives & 14 & 15.9 \\
& Healthcare professionals (eg doctors, & 5 & 9.7 \\
\hline Willingness to get & nurses) & 138 & 3.4 \\
information on CAM & Yes & 7 & 95.2 \\
methods & No & & 4.8 \\
\hline
\end{tabular}

*There were multiple answers.

The knowledge and opinions of parents regarding CAM therapies are shown in Table 4. Some $81.4 \%$ of the parents agreed with the statement "I hide the fact that I use CAM 
therapies from healthcare professionals"; $44.8 \%$ agreed with "I shy away from asking healthcare professionals questions about CAM therapies"; and 36.6\% agreed with "I think healthcare professionals will judge me for using CAM therapies." In contrast, statements of "Using CAM therapies alone is more effective"; "CAM therapies may affect treatment negatively"; and "CAM therapies can be used throughout the duration of the disease" were answered with "not sure" by nearly half of the parents (Table 4).

Table 4. Knowledge and Opinions of Parents Regarding Complementary and Alternative Medicine ( $\mathrm{n}=145$ ) (Agree:A, Not Sure:NS, Disagree:D)

\begin{tabular}{|c|c|c|c|}
\hline & A & NS & D \\
\hline 1. I hide the fact that I use CAM methods. & $\mathbf{8 1 . 4}$ & 11.0 & 7.6 \\
\hline $\begin{array}{c}\text { 2. I believe CAM methods are effective while applied with the } \\
\text { medical treatment. }\end{array}$ & 31.0 & 40.7 & 28.3 \\
\hline 3. Using CAM therapies alone is also effective. & 38.0 & $\mathbf{4 9 . 0}$ & 13.0 \\
\hline $\begin{array}{c}\text { 4. CAM therapies can be applied throughout the duration of the } \\
\text { disease. }\end{array}$ & 24.1 & $\mathbf{5 2 . 5}$ & 23.4 \\
\hline $\begin{array}{c}\text { 5. I shy away from asking healthcare professionals questions about } \\
\text { CAM therapies. }\end{array}$ & $\mathbf{4 4 . 8}$ & 38.6 & 16.6 \\
\hline $\begin{array}{c}\text { 6. CAM practices can be applied by a non-healthcare professional } \\
\text { (Lokman physicians, herbalists etc.). }\end{array}$ & 24.5 & $\mathbf{4 1 . 4}$ & 24.2 \\
\hline $\begin{array}{c}\text { 7. CAM practices should be carried out under the supervision of } \\
\text { only healthcare professionals (nurses, physicians etc.). }\end{array}$ & 31.7 & $\mathbf{4 7 . 6}$ & 20.7 \\
\hline $\begin{array}{c}\text { 8. I believe CAM methods could have positive effects on the } \\
\text { patient. }\end{array}$ & 22.1 & $\mathbf{4 5 . 5}$ & 32.4 \\
\hline $\begin{array}{c}\text { 9. I think important responsibilities fall on parents with CAM } \\
\text { practices. }\end{array}$ & 17.3 & 36.6 & $\mathbf{4 6 . 2}$ \\
\hline $\begin{array}{c}\text { 10. I think healthcare staff will judge me because I use CAM } \\
\text { methods. }\end{array}$ & 36.6 & $\mathbf{4 5 . 5}$ & 19.9 \\
\hline $\begin{array}{c}\text { 11. I believe CAM methods also have adverse effects. } \\
\text { 12. Healthcare professionals should provide information about }\end{array}$ & 26.2 & $\mathbf{4 3 . 4}$ & 30.4 \\
\hline $\begin{array}{c}\text { CAM practices to parents and patients. } \\
\text { 13. The adverse effects of CAM methods can affect the medical } \\
\text { treatment in a negative way. }\end{array}$ & 26.9 & $\mathbf{4 2 . 8}$ & 30.3 \\
\hline $\begin{array}{c}\text { 14. Parents and children have the right to demand information } \\
\text { about CAM. }\end{array}$ & 20.0 & 33.1 & $\mathbf{5 4 . 5}$ \\
\hline $\begin{array}{c}\text { 15. I would like to get information on CAM therapies from } \\
\text { healthcare professionals (eg doctors, nurses). }\end{array}$ & 17.9 & 27.6 & $\mathbf{5 3 . 5}$ \\
\hline $\begin{array}{c}\text { 16. Parents and children have the right to use CAM methods, if } \\
\text { they wish to do so. }\end{array}$ & 17.2 & 37.9 & $\mathbf{4 4 . 9}$ \\
\hline $\begin{array}{c}\text { 17. Parents who use CAM methods should inform healthcare } \\
\text { professionals. }\end{array}$ & 29.7 & $\mathbf{5 1 . 0}$ \\
\hline $\begin{array}{c}\text { 18. Using CAM methods alongside with medical treatment } \\
\text { shortens the treatment process. }\end{array}$ & $\mathbf{4 6 . 9}$ & 23.4 \\
\hline
\end{tabular}

\section{Discussion}

The incidence of childhood cancer has gradually increased, and is among the most lifethreatening diseases in Turkey, as well as in the world. Pediatric patients with cancer who receive conventional treatment are often given CAM therapies to reduce or remove symptoms that appear in the course of treatment. 
In our study, all parents had used CAM therapies during their child's treatment. Kilicarslan Toruner et al. [9] reviewed 14 studies published between 1998-2008 and reported that the frequency of CAM therapy use among pediatric oncology patients was high (49.8\%), and similarly in other studies, the frequency of CAM therapy use for pediatric patients with cancer was reported to be between $31-84 \%$ [5, 12-15]. The frequency of CAM therapy use was lower in our study than in other studies. This result can be explained with the insufficiency in parents' educational backgrounds and therefore the difficulty they may have had in obtaining information.

The primary reasons for choosing CAM therapies reported among families' were stopping/treating the progression of cancer, and reducing the adverse effects of medical treatment $[2,8,11,14]$. Gottscling et. al. [5] found that CAM therapies had been used physical stabilization (29\%), to streghten the immune system (24\%). Gomez-Martinez et al. [16] discovered that CAM therapies had been used to reduce adverse effects $(53 \%)$ and fight cancer $(32 \%)$ in their study. Similarly, most of the parents in our study declared that they used CAM therapies to reduce adverse effects and support the treatment.

In a literature review by Kilicarslan Toruner et al.[9], the most frequently used CAM method by parents was determined as biologically based treatments such as plants, vitamins, and minerals. Accordingly, in a study by Yeter [17], it was found that herbal CAM methods were frequently used. This method was followed by spiritual/physical practices such as praying and dreaming, aromatherapy, and manipulative body-based treatments such as massage. In our study, $53.8 \%$ of the parents who had used CAM stated that they had used herbs, and $23.1 \%$ used spiritual/physical practices.

In the literature, parents have explained that they received information about CAM methods from their friends and relatives [2, 3, 5, 12, 16, 18]. Molassiotis and Cubbin [8] found that $69.4 \%$ of the parents in their study received information through the media and $66.7 \%$ through healthcare professionals, whereas Yeter [17] reported that families had stated that they received their related information from other patients' relatives. In our study, similar to other studies, it was found out that the parents received information about CAM through relatives/friends (37.2\%), media (22.8\%), and other patients/patients' relatives $(9.7 \%)$. The fact that most families reach information regarding CAM methods through other family members and friends shows the importance of providing reliable information that would allow for informed use of CAM.

Many studies have drawn attention to the fact that most families that use CAM therapies do not inform healthcare professionals $[2,10,14,19,20]$. In our study, we discovered that $81.4 \%$ of the parents withheld the CAM therapy use from healthcare professionals; $44.8 \%$ were hesitant to ask healthcare professionals questions about CAM therapies; and $36.6 \%$ thought they would be judged by healthcare professionals because they were using CAM methods. The fact that parents withheld CAM therapy use from healthcare professionals indicates that healthcare team members need to openly discuss the advantages and disadvantages of the use of these methods with the families of pediatric patients and without being judgmental. In order for children and families to adapt themselves to the disease and treatment and improve their coping skills, families should feel like they are included in the treatment process.

In our study, the parents answered with "Not sure" to "Using CAM therapies alone is also effective"; "The adverse effects of CAM therapies may affect the treatment negatively"; and "CAM therapies can be used throughout the duration of the disease" to statements that measured knowledge and opinions of parents regarding CAM (Table 4). This shows that parents need information on CAM methods.

The diagnosis and treatment processes of cancer deeply affect the child and parents. Parents strive to get information from sources such as relatives, healthcare professionals, media, and the internet to treat the disease and to reduce symptoms. In this period, they 
come across information and suggestions about CAM methods [16, 21]. These information and suggestions tend to increase the parents' questions and worries. Nurses should evaluate opinions, values, and information requirements of the child and parents regarding CAM methods and plan healthcare accordingly while they collect data. During this process, it makes children and parents feel more at ease about consulting healthcare professionals for information about the CAM method they are using/planning to use and expressing their thoughts and actions; it also increases nursing quality when nurses inform patients and parents without judging them in any way.

\section{Conclusion and suggestions}

After analyzing the findings, we conclude that the parents' knowledge regarding CAM methods is insufficient/ limited, and they feel the need withhold details about the use of CAM from healthcare professionals for fear of their opinion of its use. Concordantly, environments where families can discuss and get information on CAM methods should be created and training sessions should be planned by healthcare professionals.

\section{Acknowledgment}

The authors wish to thank Esra Ozpitir, Sabriye Celik, Zeynep Cetin and Merve Pasayigit for their assistance to this study. Regarding the research and/or authorship of this article, the authors didn't receive any financial

\section{References}

1. Bauer-Wu, S. Critique 1: Complementary and alternative medicine in pediatric oncology. Seminars in Oncology Nursing, 21,115-118 (2005)

2. Karadeniz, C., Pınarlı, G., Oğuz, A., Gürsel, T. \& Canter, B. CAM medicine use in a pediatric oncology unit in Turkey. Pediatric Blood Cancer, 48, 540-543 (2007)

3. Gozum, S., Arikan, B., Büyükavci, M. Complementary and alternative medicine use in pediatric oncology patients in Eastern Turkey. Cancer Nursing, 30, 38-44 (2007)

4. Quimby, E.L. The Use of Herbal Therapies in Pediatric Oncology Patients: Treating Symptoms of Cancer and Side Effects of Standard Therapies. Journal of Pediatric Oncology Nursing, 24, 35-40 (2007)

5. Gottscling, S., Meyer, S., Langler, A., Ebinger, F., Bialas P., Gronwald, B. Use of complementary and alternative medicine in diblings of pediatric cancer patients in Germany. A population- based survey. Open Journal of Pediatrics, 4, 93-101 (2014)

6. National Center of Complementary and Alternative Medicine-NCCAM (2007). Retrived from http://nccam.nih.gov/health/whatiscam/ Accessed: 05.02.2016

7. Mc Curdy, E., Spangler, J., Wofford, M., Chauvenet, A.R., McLean, T.W. Religiosity is associated with the use of complementary medical therapies by pediatric oncology patients. Journal of Pediatric Hematolog and Oncology, 25, 125-129 (2003)

8. Molassiotis, A., Cubbin, D. Thinking outside the box: complementary and alternative therapies use in paediatric oncology patients. European Journal of Oncology Nursing, 8, 50-60 (2004)

9. Kilicarslan, Toruner, E., Uysal, G., Hanoglu, Z., Algier, L. Pediatrik Onkoloji Hastalarında Tamamlayıcı ve Alternatif Tedavi Yöntemlerinin Kullanımı: Bir Literatür Taramas1. DEUHYO ED, 2, 102-109 (2009)

10. Laengler, A., Spix, C., Seifert, G., Goottschling, S., Graf, N., Kaathsch, P. Complementary and alternative treatment methods in children with cancer: A 
population-based retrospective survey on the prevalence of use in Germany. European Journal of Cancer, 44, 2233-2240 (2008)

11. Naja, F., Alameddine, M., Abboud, M., Bustami, D., Halaby, R.A. Complementary and alternative medicine use among pediatric patients with leukemia: the case of Lebanon. Integrative Cancer Therapies, 10, 38-46., (2011)

12. Fernandez, C.V., Stutzer, C.A., Macwilliam, L., Fryer, C. Alternative and complementary therapy use in pediatric oncology patients in British Columbia: Prevalence and reasons for use and nonuse. Journal of Clinical Oncology, 16, 1279$1286(1998)$

13. Kelly, K.M., Jacobson, J.B., Kennedy, D.D., Braudt, S.M., Mallick, M., Weiner, M.A. Use of Unconventional Therapies by Children with Cancer at an Urban Medical Center. Journal of Pediatric Hematology and Oncology, 22, 412-416 (2000)

14. Martel, D., Bussières, J.F., Théorêt, Y., Lebel, D., MoghrABİ, A., Laurier, C. Use of alternative and complementary therapies in children with cancer, Pediatric Blood \& Cancer, 44, 660-668 (2005)

15. Hamidah, A., Rustam, Z.A., Tamil, A.M., Zarina, L.A., Zulkifli, Z.S., \& Jamal R. Prevalence and Parental Perceptions of Complementary and Alternative Medicine Use by Children with Cancer in a Multi-Ethnic Southeast Asian Population. Pediatric Blood Cancer, 52, 70-74 (2009)

16. Gomez-Martinez, R., Tlacuilo-Parra, A., Garibaldi-Covarrubias, R. Use of complementary and alternative medicine in children with cancer in Occidental, Mexico. Pediatric Blood and Cancer, 49, 820-823 (2006)

17. Yeter G. Çocuk kanser hastalarında semptomlara yönelik tamamlayıcı ve alternatif tedavi kullanımı. (Yükseklisans Tezi, Mersin Üniversitesi, Sağlık Bilimleri Enstitüsü, Hemşirelik Anabilim Dalı) (2012)

18. Araz, N., Bülbül, S. Use of complementary and alternative medicine in a pediatric population in southern Turkey. Clinical Invest Medicine, 34, 21-29 (2011)

19. Yeh, C.H., Tsai, J.L., Li, W., Chen, H.M., Lee, S.C., Lin, C.F., Yang, C.P. Alternative therapy in pediatric patients in Taiwan. Journal of Pediatric Hematology and Oncology, 17, 55- 65 (2000)

20. June, B., Anne, L. Unconventional therapy use among children with cancer in Saskatchewan. Journal of Pediatric Oncology Nursing, 18, 16-25 (2001)

21. Genc, R.E., Senol, S., Turgay, A.S., Kantar, M. Complementary and alternative medicine used by pediatric patients with cancer in western Turkey. Oncology Nursing Forum, 36, 159-164 (2009) 